\title{
Sexual dimorphism in the Spotted Stinger Inimicus sinensis (Valenciennes, 1833) and notes on pore structures on the body
}

\author{
Emmanuel S. Delloro Jr. ${ }^{1,2,3}$, Hiroyuki Motomura ${ }^{2,3}$ and Ricardo P. Babaran ${ }^{1^{*}}$
}

\begin{abstract}
Spotted stinger individuals, Inimicus sinensis, collected from Carles, Iloilo, Philippines exhibited previously-unreported sexual dimorphism. Thirty-three morphological measurements, including standard length, and fourteen meristic counts from 99 specimens (47 males and 52 females) were analyzed for sexual dimorphism. Most morphometric characters differed significantly between the sexes, whereas no differences were found in meristic counts. Dorsal and anal-fin and free pectoral-fin ray lengths were greater in male specimens. On the other hand, the head and body region were relatively larger in female specimens. Principal Component Analysis (PCA) extracted two principal components from significantly different parameters, which explained $62.29 \%$ of the cumulative variances. Variations in the two major components resulted from: head width, upper jaw, lower jaw, snout, pre-dorsal, pre-anal-fin, and anal-fin base lengths in PC1 (45.65 $\%)$; and orbit diameter and anal-fin base length in PC2 (16.64 \%). Additionally, a single anterolateral pore on the body and pores above the lateral-line are described, although no evidence of association with other organs was found.
\end{abstract}

Keywords: morphology, meristics, factor analysis, sac

\section{Introduction}

The Spotted Stinger Inimicus sinensis (Valenciennes, 1833) (Synanceiidae: Choridactylinae), characterized by distinct irregular white to yellow blotches on the inner surface of the pectoral fin, and a snout length equal to or greater than the postorbital length (Eschmeyer et al.,1979; Inaba \& Motomura, 2018), is widely distributed on silt or sandy bottoms in the eastern Indian and western Pacific oceans (Inaba \& Motomura, 2018). The species is known to be venomous, a common characteristic of the genus, having venomous spines, each with an anterolateral groove connected to a venom gland (Smith \& Wheeler, 2006).

Sexual dimorphism, a common phenomenon in animal taxa (Herler et al., 2010), has been widely observed in teleost fishes (Parker, 1992), including for example, cichlids (Oliveira \&

\footnotetext{
${ }^{1}$ Institute of Marine Fisheries and Oceanology, College of Fisheries and Ocean Sciences, University of the Philippines Visayas, 5023 Miagao, Iloilo, Philippines

${ }^{2}$ Graduate School of Fisheries, Kagoshima University, 4-50-20

Shimoarata, Kagoshima 890-0056, Japan

${ }^{3}$ The Kagoshima University Museum, 1-21-30 Korimoto, Kagoshima 890-0065, Japan

*Corresponding email: delloroedjr@gmail.com; rpbabaran@up.edu.ph

Date Submitted: 10 June 2019

Date Accepted: 05 November 2019
}

Almada, 1995; Herler et al., 2010; Bhatta et al., 2012; Ibor et al., 2017), flounders (Kobelkowsky, 2004) and minnows (Ostrand et al., 2001). Many aspects of functional performances of fishes, especially in feeding and locomotion, are directly related to their morphological features and limitations (Schoenfuss \& Blob, 2007). Therefore, an understanding of sexually differentiated morphology and characteristics within a species may provide insights that prove critical for management and conservation of a particular fish population.

Because sexual dimorphism had not been previously reported in the genus Inimicus, the present study investigated the presence of secondary sexual characteristics in I. sinensis, in addition to describing pores on the body between the opercular margin and upper end of the pectoral fin base, and above the lateral-line.

\section{Materials and Methods}

Collection of specimens. Specimens were collected at 20 $40 \mathrm{~m}$ water depth by bottom otter trawl from December 2017 to February 2018 in Carles, Iloilo, Philippines. Curatorial procedures followed Motomura \& Ishikawa (2013). Counts and measurements followed Eschmeyer (1969), Eschmeyer et al. (1979) and Inaba \& Motomura (2018). Counts of lateral-line tubed pores included all pores, including two (2) separated pores that occurred on the caudal fin in some specimens. Pores above the lateral-line tubed pores were also counted. Identification of the specimens followed Eschmeyer et al. (1979) and Inaba \& 
Motomura (2018).

Sex identification. Sex of specimens was initially determined by dissection of the belly and macroscopic examination of the gonad. Subsequent microscopic confirmation followed Takashima \& Hibiya's (1995) identification guide for male and female gonads. Gonads were prepared for histological analysis following conventional methods of dehydrating, embedding, sectioning, and staining with hematoxylin and eosin. Finished slides were examined and photographed under a stereo microscope (Nikon, SMZ18). Gonads with spermatocytes were classed as male, those with oocytes being classed as female.

Morphometric characters and meristic counts. A total of 33 morphometric characters were measured on each specimen using a digital caliper (rounded to the nearest $0.01 \mathrm{~mm}$ ), in addition to 14 meristic counts. Minute characters, such as gill rakers and lateral-line tubed pores, were counted using a dissecting microscope.

Analysis of the specimen. Standard and head lengths are abbreviated as SL and HL, respectively. All measurements were transformed as ratios of standard length (SL) prior to comparison in order to eliminate variability that could occur as a result of allometric growth. Transformed data were analyzed by arithmetic means, standard deviations and variability coefficients. Independent sample t-Test was used to determine those morphometric characters differing significantly between sexes, in addition to Principal Component Analysis (PCA). All analyses were tested at $95 \%$ confidence level, corrected with Bonferroni Correction. SPSS 16.0 and R software were used for the analysis.

Description of pores. The single anterolateral pore between the opercular margin and upper part of the pectoral-fin base was described through dissection and staining. Ten (10) selected samples were used for staining of the pore (using the same method used for gonads), the stained specimens subsequently being photographed. The remaining samples were examined under a dissecting microscope. Pore length and width were measured using a digital caliper, rounded to the nearest 0.01 $\mathrm{mm}$.

\section{Results and Discussion}

Morphology and meristics. A total of 99 I. sinensis (47 male and 52 female) collected by bottom otter trawl from Carles, Iloilo, Philippines were used in this study. Standard length (SL) ranged from 83.6 to $190.3 \mathrm{~mm}(128.3 \pm 29.1)$ for all specimens, males ranging from 86.8 to $152.3 \mathrm{~mm}(112.7 \pm 18.2)$ and females from 83.6 to $190.3 \mathrm{~mm}(142.4 \pm 30.0)$. Variability coefficients were within a relatively large range from 2.29 to
$22.68 \%$. For the first time, this study revealed sexual dimorphism in $I$. sinensis and for the entire genus Inimicus. There are different possible reasons for this observation. Wearmouth \& Sims (2008) reported that spatial segregation by sex has been reported in fishes. The social behavior of Inimicus has not yet been fully observed and reported, but Eschmeyer et al. (1979) reported that Inimicus fishes modified themselves morphologically to adapt to the substrate effectively and to catch their prey efficiently. Also the method of collecting the specimen might have affected the size range of the samples; the bigger female $I$. sinensis were probably more susceptible to trawling operation compared to large males. However, sexual dimorphism has already been reported in some scorpaeniform fishes. Some species such as rockfishes (Lenarz \& Echeverria, 1991), scorpionfishes (Ferri et al., 2010; Peskov \& Manilo, 2016), and stonefishes (Fewings \& Squire, 1999) have been shown to have differences in morphology between sexes.

Morphometric parameters for all samples, including range, mean and coefficient of variation (among and between sexes) are presented in Table 1. Most morphometric characters of $I$. sinensis showed specific differences between sexes. Females had significantly greater head width and head, snout, upper-jaw, lower-jaw, pre-dorsal, pre-anal, and standard length than males, whereas orbit diameter and anal-fin base lengths were significantly greater in males. Lengths of the dorsal- (1st, 2nd, 3rd, 4th, 5th, 15th, 16th, and 17th spines), anal- (1st and 2nd spines), caudal-, and pectoral-fin rays (including free ray) were significantly greater in males. The coefficient of variation of external features (fin spine and ray lengths) was high $(>10 \%)$, but only SL, body width and orbit diameter showed high variability in body features.

Female I. sinensis was clearly larger relative to males, having greater pre-anal length, body depth, and body width. Hedrick \& Temeles (1989) considered that such variations may be the result of fish adaptation to sexual selection, reproduction and food competition. Parker (1992) also mentioned that it was advantageous for females to be larger in order to have higher fecundity. Similarly, the variations observed in the present study might be linked to reproduction. Some head proportions differed between the sexes, head width and jaw, head, and snout lengths being greater in females, and orbit diameters greater in males. In the case of mouthbrooder fishes, reproductive success depends upon buccal morphology (Okuda et al., 1998; Barnett \& Bellwood, 2005; Herler et al., 2010). However, in I. sinensis, variations in the head region more likely reflected adaptations in a bottom dwelling fish for attacking possible prey, as discussed by Eschmeyer et al. (1979).

The distribution frequency of meristic characters showed no differences between sexes (Table 2). All parameters had the 
Table 1. Morphometric variables of male $(\mathrm{n}=47)$ and female $(\mathrm{n}=52)$ I. sinensis. Mean \pm standard deviation (SD), coefficient variation (CV \%), total coefficient variability of all specimens for each parameter (TV\%), minimum and maximum values (Min Max). Asterisk (*) indicates significant difference between sexes based on independent sample t-Test, corrected with Bonferroni correction $(\mathrm{p} \leq 0.0015)$. Bold font indicates higher variability coefficient $(>10 \%)$.

\begin{tabular}{|c|c|c|c|c|c|c|c|}
\hline \multirow[t]{2}{*}{ Morphometric characters } & \multicolumn{3}{|c|}{ Male I. sinensis } & \multicolumn{3}{|c|}{ Female I. sinensis } & \multirow[b]{2}{*}{ TV\% } \\
\hline & Range & Mean \pm SD & $\begin{array}{l}\text { CV } \\
\% \\
\end{array}$ & Range & Mean \pm SD & $\begin{array}{l}\text { CV } \\
\% \\
\end{array}$ & \\
\hline Standard length & $86.82-152.33$ & $112.73 \pm 18.22$ & 16.16 & $83.62-190.27$ & $* 142.38 \pm 30.05$ & 21.10 & 22.68 \\
\hline Body depth & $21.61-27.81$ & $24.94 \pm 1.33$ & 5.32 & $21.34-28.82$ & $25.66 \pm 1.72$ & 6.72 & 6.24 \\
\hline Body width & $16.93-31.54$ & $21.13 \pm 2.82$ & 13.35 & $17.42-28.97$ & $22.70 \pm 2.95$ & 13.00 & 13.58 \\
\hline Head length & $31.43-35.71$ & $33.69 \pm 1.11$ & 3.29 & $32.06-37.88$ & $34.28 \pm 1.20$ & 3.51 & 3.5 \\
\hline Head width & $21.76-28.96$ & $24.93 \pm 1.60$ & 6.43 & $22.80-31.95$ & $* 26.19 \pm 1.93$ & 7.36 & 7.35 \\
\hline Snout length & $13.02-15.45$ & $14.26 \pm 0.60$ & 4.18 & $13.78-16.20$ & $* 14.84 \pm 0.59$ & 3.99 & 4.52 \\
\hline Orbit diameter & $6.45-8.57$ & $* 7.24 \pm 0.51$ & 7.01 & $5.53-7.27$ & $6.18 \pm 0.48$ & 7.8 & 10.87 \\
\hline Interorbital width at midline of eye & $7.3-12.1$ & $9.55 \pm 1.14$ & 11.91 & $7.57-11.14$ & $9.78 \pm 0.73$ & 7.46 & 9.79 \\
\hline Upper-jaw length & $11.78-16.07$ & $14.28 \pm 0.86$ & 5.99 & $13.32-17.28$ & $* 15.26 \pm 0.71$ & 4.66 & 6.22 \\
\hline Lower-jaw length & $15.82-20.50$ & $17.96 \pm 0.98$ & 5.45 & $16.79-20.70$ & $* 18.86 \pm 0.93$ & 4.91 & 5.69 \\
\hline Postorbital length & $12.36-15.04$ & $13.66 \pm 0.64$ & 4.65 & $11.74-15.94$ & $13.71 \pm 0.88$ & 6.45 & 5.64 \\
\hline Pre-dorsal-fin length & $22.42-26.43$ & $24.21 \pm 1.01$ & 4.15 & $22.25-26.97$ & $* 25.12 \pm 0.94$ & 3.72 & 4.32 \\
\hline Pre-anal-fin length & $51.33-58.94$ & $54.99 \pm 1.95$ & 3.55 & $53.93-62.23$ & $* 58.07 \pm 1.70$ & 2.93 & 4.21 \\
\hline Pre-pelvic-fin length & $22.84-29.82$ & $25.97 \pm 1.64$ & 6.31 & $23.09-30.85$ & $26.72 \pm 1.52$ & 5.67 & 6.11 \\
\hline 1st dorsal-fin spine length & $13.24-19.35$ & $* 16.42 \pm 1.33$ & 8.13 & $11.44-19.65$ & $15.11 \pm 1.63$ & 10.82 & 10.38 \\
\hline 2nd dorsal-fin spine length & $16.31-25.71$ & $* 21.34 \pm 2.03$ & 9.52 & $13.29-24.85$ & $19.16 \pm 2.45$ & 12.78 & 12.38 \\
\hline 3rd dorsal-fin spine length & $16.66-23.35$ & $* 20.55 \pm 1.62$ & 7.89 & $13.52-23.75$ & $18.65 \pm 2.45$ & 13.12 & 11.77 \\
\hline 4th dorsal-fin spine length & $15.05-26.18$ & $* 21.78 \pm 2.11$ & 9.69 & $13.43-24.17$ & $19.62 \pm 2.13$ & 10.86 & 11.48 \\
\hline 5th dorsal-fin spine length & $16.53-25.81$ & $* 21.97 \pm 2.14$ & 9.76 & $11.39-24.34$ & $19.69 \pm 2.38$ & 12.10 & 12.2 \\
\hline 15th dorsal-fin spine length & $14.66-22.32$ & $* 19.25 \pm 1.91$ & 9.91 & $12.17-21.93$ & $17.96 \pm 1.82$ & 10.15 & 10.57 \\
\hline 16th dorsal-fin spine length & $15.10-21.01$ & $* 17.76 \pm 1.44$ & 8.08 & $11.92-20.95$ & $16.27 \pm 1.80$ & 11.08 & 10.57 \\
\hline 17th dorsal-fin spine length & $14.94-19.89$ & $* 17.43 \pm 1.30$ & 7.47 & $11.60-19.51$ & $15.86 \pm 1.67$ & 10.50 & 10.23 \\
\hline 18th dorsal-fin spine length & $16.22-20.75$ & $17.87 \pm 1.47$ & 8.22 & $11.90-17.42$ & $15.55 \pm 2.04$ & 13.12 & 1152 \\
\hline 1st anal-fin spine length & $5.62-9.65$ & $* 7.38 \pm 0.88$ & 11.96 & $4.06-8.29$ & $5.95 \pm 1.06$ & 17.74 & 18.27 \\
\hline 2nd anal-fin spine length & $7.05-12.69$ & $* 9.13 \pm 1.22$ & 13.40 & $6.31-10.46$ & $7.74 \pm 0.94$ & 12.09 & 15.26 \\
\hline Pectoral-fin ray length & $33.87-43.10$ & $* 37.78 \pm 1.97$ & 5.22 & $31.22-38.07$ & $34.95 \pm 1.60$ & 4.57 & 6.27 \\
\hline
\end{tabular}


Table 1. (continued)

\begin{tabular}{lccccccc}
\hline \multicolumn{1}{c}{ Morphometric characters } & \multicolumn{3}{c}{ Male I. sinensis } & \multicolumn{3}{c}{ Female I. sinensis } \\
\hline & Range & Mean \pm SD & $\begin{array}{c}\text { CV } \\
\%\end{array}$ & Range & Mean \pm SD & $\begin{array}{c}\text { CV } \\
\%\end{array}$ & TV\% \\
\hline Pelvic-fin spine length & $8.83-14.58$ & $11.88 \pm 1.33$ & 11.22 & $9.97-13.85$ & $11.26 \pm 0.98$ & 8.70 & $\mathbf{1 0 . 3 6}$ \\
Caudal-fin length & $26.50-35.25$ & $* 29.42 \pm 2.08$ & 7.07 & $23.19-32.07$ & $27.90 \pm 2.01$ & 7.19 & 7.58 \\
Dorsal-fin base length & $66.34-71.13$ & $68.98 \pm 1.19$ & 1.72 & $64.52-71.72$ & $68.12 \pm 1.76$ & 2.58 & 2.29 \\
Anal-fin-base length & $33.31-40.19$ & $* 36.9 \pm 1.52$ & 4.12 & $33.02-38.21$ & $35.49 \pm 1.32$ & 3.72 & 4.37 \\
Pectoral-fin base length & $12.38-15.30$ & $13.67 \pm 0.71$ & 5.20 & $12.89-15.33$ & $14.03 \pm 0.61$ & 4.34 & 4.9 \\
1st free pectoral-fin ray length & $23.26-33.19$ & $27.55 \pm 2.00$ & 7.26 & $20.18-29.49$ & $26.06 \pm 1.87$ & 7.19 & 4.71 \\
2nd free pectoral-fin ray length & $20.89-29.09$ & $* 25.26 \pm 1.73$ & 6.86 & $20.88-27.95$ & $24.53 \pm 1.41$ & 5.73 & 6.44 \\
\hline
\end{tabular}

same modes, except dorsal-fin soft rays and gill rakers, with females having higher modes than male specimens.

PCA was conducted on the 8 morphometric characters in body features that showed significant differences, excluding the external features. Two principal components were extracted with eigenvalues greater than 1.00 , accounting for $62.25 \%$ of the cumulative variances (Table 3; Fig. 1). Seven (7) variables were correlated with PC1 (strongly correlated ( $|\mathrm{r}| \geq 0.7$ ), moderately correlated $(|\mathrm{r}|<0.7))$. Head width $(\mathrm{r}=-0.6)$, snout length $(\mathrm{r}=-0.8)$, upper jaw $(\mathrm{r}=-0.8)$, lower jaw $(\mathrm{r}=-0.7)$, predorsal-fin $(\mathrm{r}=-0.7)$, and pre-anal-fin base $(\mathrm{r}=-0.7)$ were negatively correlated with component 1 . By contrast, only analfin base $(\mathrm{r}=0.5)$ was positively correlated with component 1 . With respect to component 2 , orbit diameter $(\mathrm{r}=-0.7)$ and analfin base $(\mathrm{r}=-0.5)$ were negatively correlated while pre-anal-fin base $(\mathrm{r}=0.45)$ was positively correlated (Table 4$)$.

Sexual dimorphism, previously unreported in the genus, was confirmed in Inimicus sinensis. Such dimorphism has also been reported in other scorpaeniform species. Fewings and Squire (1999) noted that male Synanceia horrida, an estuarine stonefish, was much smaller than females, with similar variations observed in Scorpaena porcus (Ferri et al., 2010; Peskov \& Manilo, 2016) and Scorpaena onaria (Motomura et al., 2005). The variations observed in $I$. sinensis were not limited to morphological characters but were likely related to physiological characteristics and appearance.

Secondary sexual characteristics in $I$. sinensis were observed in both external features and body proportions. Male external features that were significantly longer compared with females included dorsal-, anal-, and pelvic-fin spine lengths, which had higher variability coefficients $(>10 \%)$. According to Carvalho (1993), the coefficient variability within a fish population is at least $10 \%$, which is greater than in most

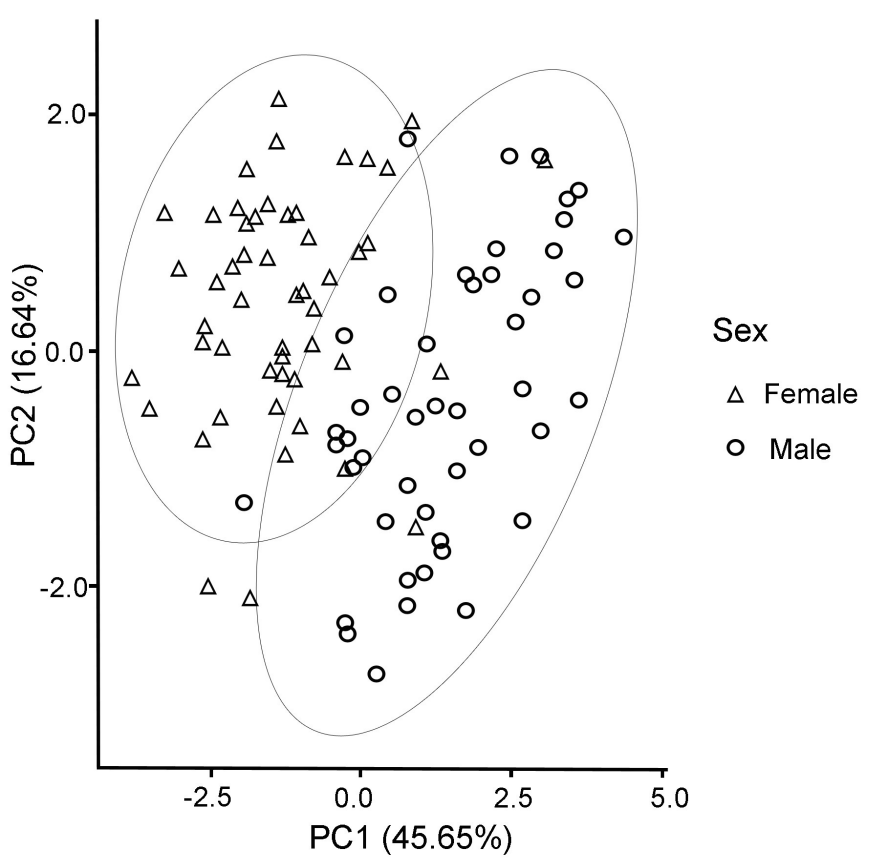

Figure 1. Scatter plot of first two components (PC1 and PC2) of PCA of selected morphometric data for male and female I. sinensis from Carles, Iloilo, Philippines. The clusters of the male and female I. sinensis ordinated by PCA are overlapped.

terrestrial vertebrates. Ferri et al. (2010) reported a relatively high range of coefficient variability (2.64-17.89\%) in S. porcus, similar to that found here in I. sinensis (2.29-22.68\%). However, Ferri et al. (2010) considered that the variability in $S$. porcus was insufficient for sex differentiation due to an overlap of morphometric characters. Overlapping in morphometric characters was also observed in I. sinensis (Fig. 1). The overlap was size related, thus, male and female $I$. sinensis with almost the same size were morphologically similar. The variations 


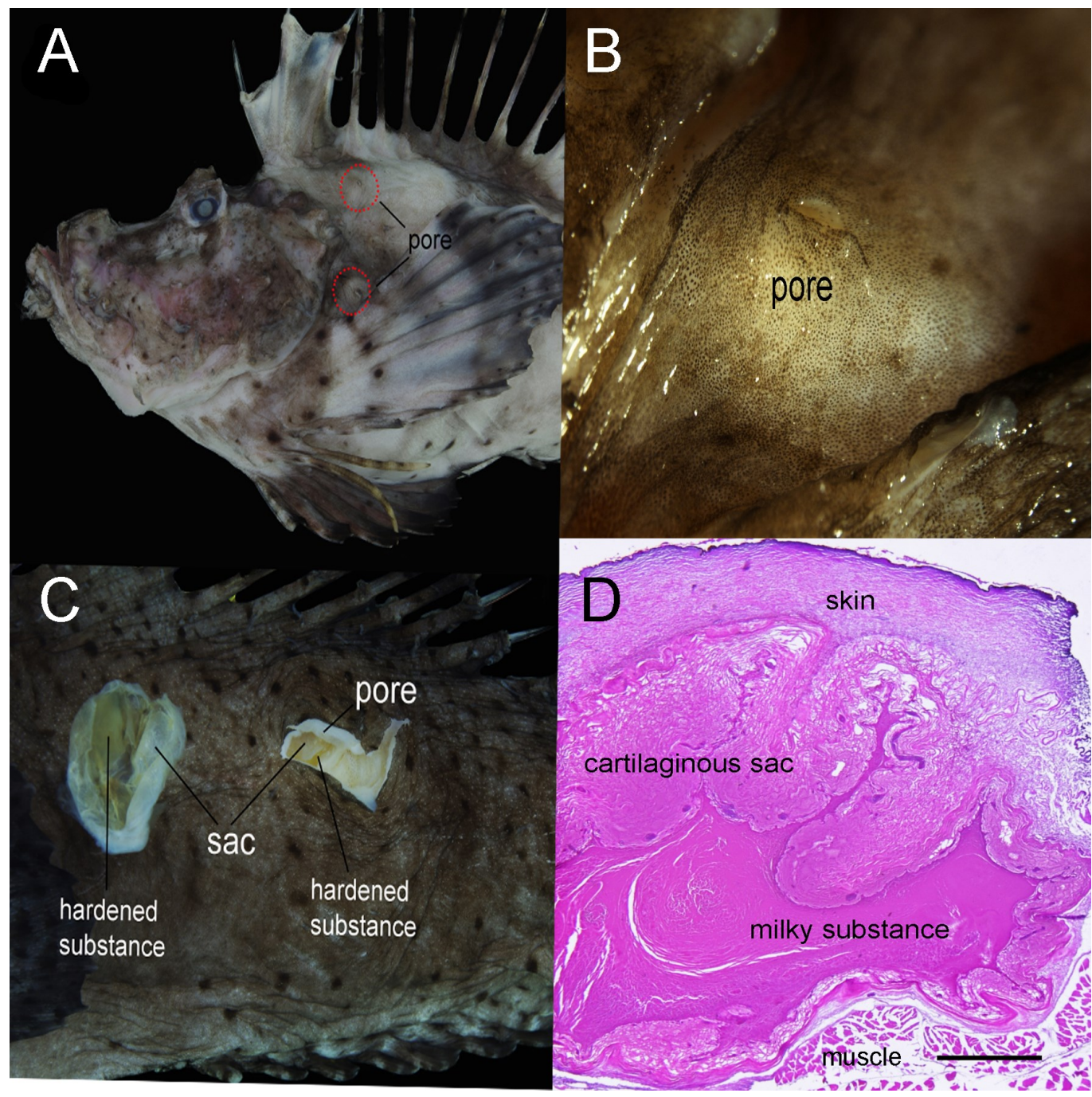

Figure 2. Pores on the body of Inimicus sinensis. A-B) Anterolateral pore behind opercular margin and small pores above lateral-line. C) Hardened substance found inside sacs connected to pores. D) Stained cross section of pore behind opercular margin. Scale $=1 \mathrm{~mm}$.

observed in this study might be linked with the maturity and reproduction of the fish. Female $I$. sinensis was observed to grow bigger, in terms of head and body region, than the male.

Physiological characteristics and appearance of organisms are commonly used to distinguish them from their conspecifics. Motomura et al. (2005) reported that male S. onaria had a black blotch on the margin of the dorsal-fin spine, which was absent in females. In the case of $I$. sinensis, differences in skin color and patterns were also noted, in particular, distinct blotches inside the pectoral fin, such being absent in other devil stinger fishes (Eschmeyer et al.,1979; Inaba \& Motomura, 2018). Variations in skin color of $I$. sinensis were also observed, although unsuitable for sex identification due to the likelihood of their being habitat-related.
Description of pores. Inimicus sinensis was observed to have a single anterolateral pore behind the opercular margin and near the upper end of the pectoral-fin base (Fig. 2A). The pore was connected to a cartilaginous sac [length and width 7.7-21.1 $\mathrm{mm}(13.3 \pm 3.2)$ and $2.9-12.6 \mathrm{~mm}(6.3 \pm 2.0)$, respectively] under the skin. No differences were apparent between sexes in length or width of the sac when expressed as a ratio to standard length. Three to five small pores covered with a dermal flap and with an attached sac underneath the skin were also observed above the lateral-line in all specimens (both sexes) (Figs. 4.D-G).

Each pore-connected sac under the skin, supported by a postcleithrum spine that occurred as a single, double, forked, or curved element (Fig. 4), and covered with connective tissue and fat (Fig. 2D), lacked any apparent association with any major organ. However, the sacs were thinner and smaller compared to 
Table 2. Frequency distribution of meristic characters in male $(\mathrm{n}=47)$ and female $(\mathrm{n}=52)$ Inimicus sinensis. Bold number indicates mode.

Dorsal-fin spines and soft rays

\begin{tabular}{|c|c|c|c|c|c|c|c|c|c|c|c|}
\hline & \multicolumn{4}{|c|}{ Dorsal-fin spines } & \multicolumn{3}{|c|}{ Dorsal-fin soft rays } & \multicolumn{4}{|c|}{ Total dorsal-fin rays } \\
\hline & 15 & 16 & 17 & 18 & 7 & 8 & 9 & 23 & 24 & 25 & 26 \\
\hline Male & 1 & 2 & 32 & 12 & 1 & 24 & 22 & 1 & 2 & 11 & 33 \\
\hline Female & & 1 & 44 & 7 & 3 & 13 & 36 & & & 13 & 39 \\
\hline
\end{tabular}

\begin{tabular}{|c|c|c|c|c|c|c|c|c|c|c|c|c|c|c|}
\hline & \multicolumn{4}{|c|}{ Anal-fin spines } & \multicolumn{5}{|c|}{ Anal-fin soft rays } & \multicolumn{5}{|c|}{ Total anal-fin rays } \\
\hline & 0 & 1 & 2 & 3 & 9 & 10 & 11 & 12 & 13 & 11 & 12 & 13 & 14 & 15 \\
\hline Male & 1 & 1 & 44 & 1 & 1 & 1 & 10 & 34 & 1 & 2 & 1 & 9 & 34 & 1 \\
\hline Female & & & 51 & 1 & & & 7 & 43 & 2 & & & 6 & 44 & 2 \\
\hline
\end{tabular}

\begin{tabular}{|c|c|c|c|c|c|c|c|c|c|c|c|}
\hline \multicolumn{12}{|l|}{ Pores } \\
\hline & \multicolumn{7}{|c|}{ Lateral-line tubed pores } & $\begin{array}{c}\text { Pores above } \\
\text { pectoral-fin-base }\end{array}$ & \multicolumn{3}{|c|}{ Pores at upper body } \\
\hline & 11 & 12 & 13 & 14 & 15 & 16 & 17 & 1 & 3 & 4 & 5 \\
\hline Male & & 1 & 9 & 17 & 11 & 8 & 1 & 47 & 6 & 35 & 6 \\
\hline Female & 1 & 3 & 9 & 19 & 13 & 5 & 2 & 52 & 5 & 39 & 8 \\
\hline
\end{tabular}

Upper and lower gill rakers

\begin{tabular}{lllllllllll}
\hline & \multicolumn{3}{c}{ Upper gill rakers } & \multicolumn{3}{c}{ Lower gill rakers } & \multicolumn{3}{c}{ Total gill rakers } \\
\hline & 1 & 2 & 3 & 6 & 7 & 8 & 8 & 9 & 10 & 11 \\
Male & 2 & $\mathbf{2 8}$ & 17 & 4 & $\mathbf{2 8}$ & 18 & 1 & $\mathbf{2 3}$ & 19 & 4 \\
Female & 1 & $\mathbf{3 1}$ & 20 & 9 & $\mathbf{2 9}$ & 14 & 7 & 17 & $\mathbf{2 5}$ & 3 \\
\hline
\end{tabular}

Caudal- and pelvic-fin rays

\begin{tabular}{lccccc}
\hline & \multicolumn{2}{c}{ Caudal-fin rays } & Pelvic-fin spine & Pelvic-fin rays \\
\hline & 12 & 13 & 14 & 1 & 5 \\
Male & 1 & 2 & $\mathbf{4 4}$ & $\mathbf{4 7}$ & $\mathbf{4 7}$ \\
Female & & & $\mathbf{5 2}$ & $\mathbf{5 2}$ & $\mathbf{5 2}$
\end{tabular}

Pectoral-fin rays

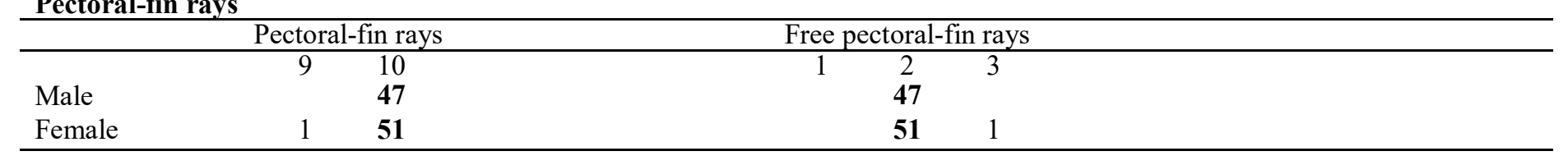



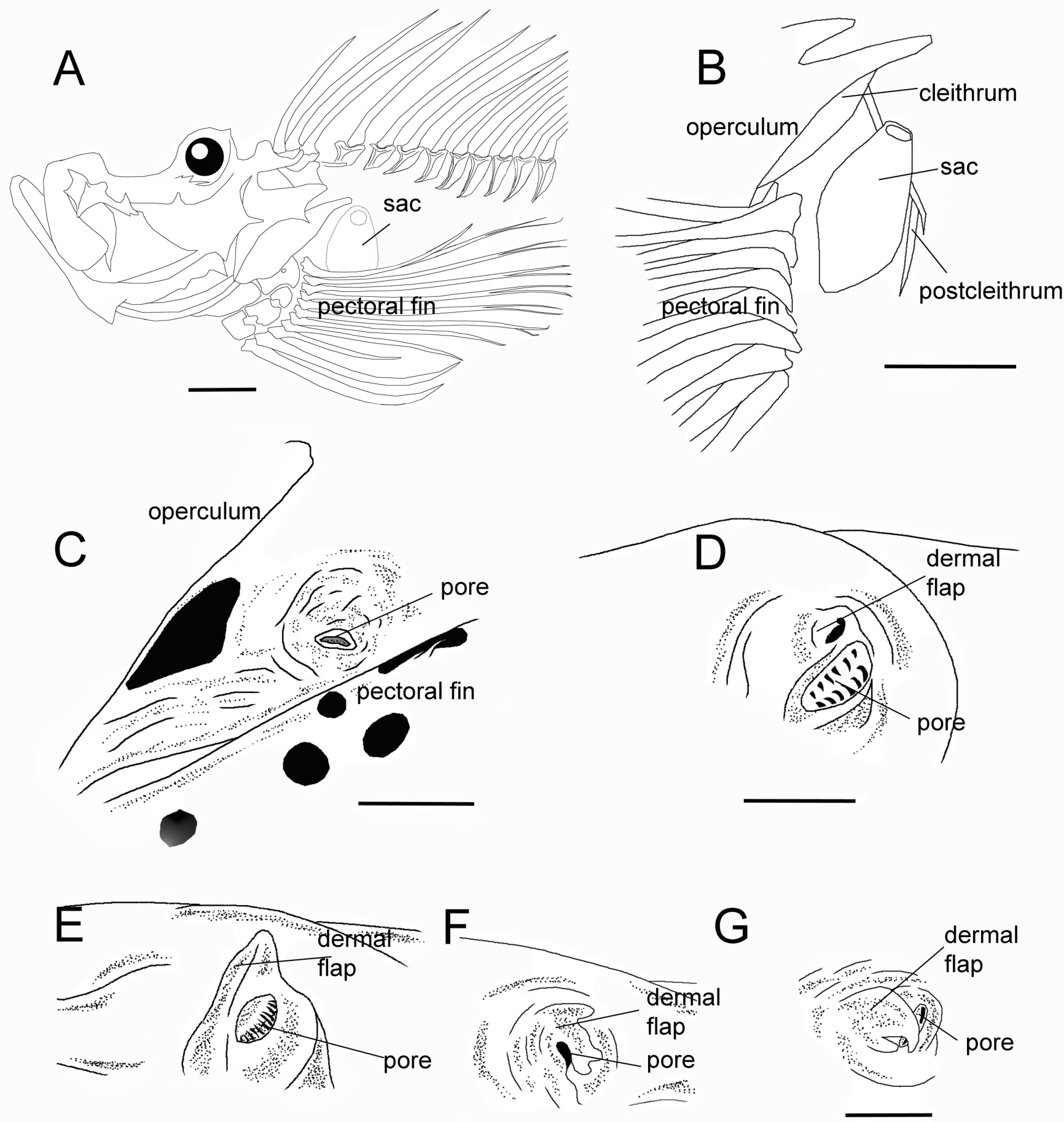

Figure 3. Sketches of the anterolateral pore and sac in Inimicus sinensis. (A-C) Pore on anterolateral surface of body connected to a sac supported by postcleithrum spine. (D-G) Small pore above lateral-line. Scale bar; A-C = $5 \mathrm{~mm}, \mathrm{D}-\mathrm{G}=1$ mm. A-B, female, $85.1 \mathrm{~mm}$ SL. C-G, female, $180 \mathrm{~mm}$ SL. 

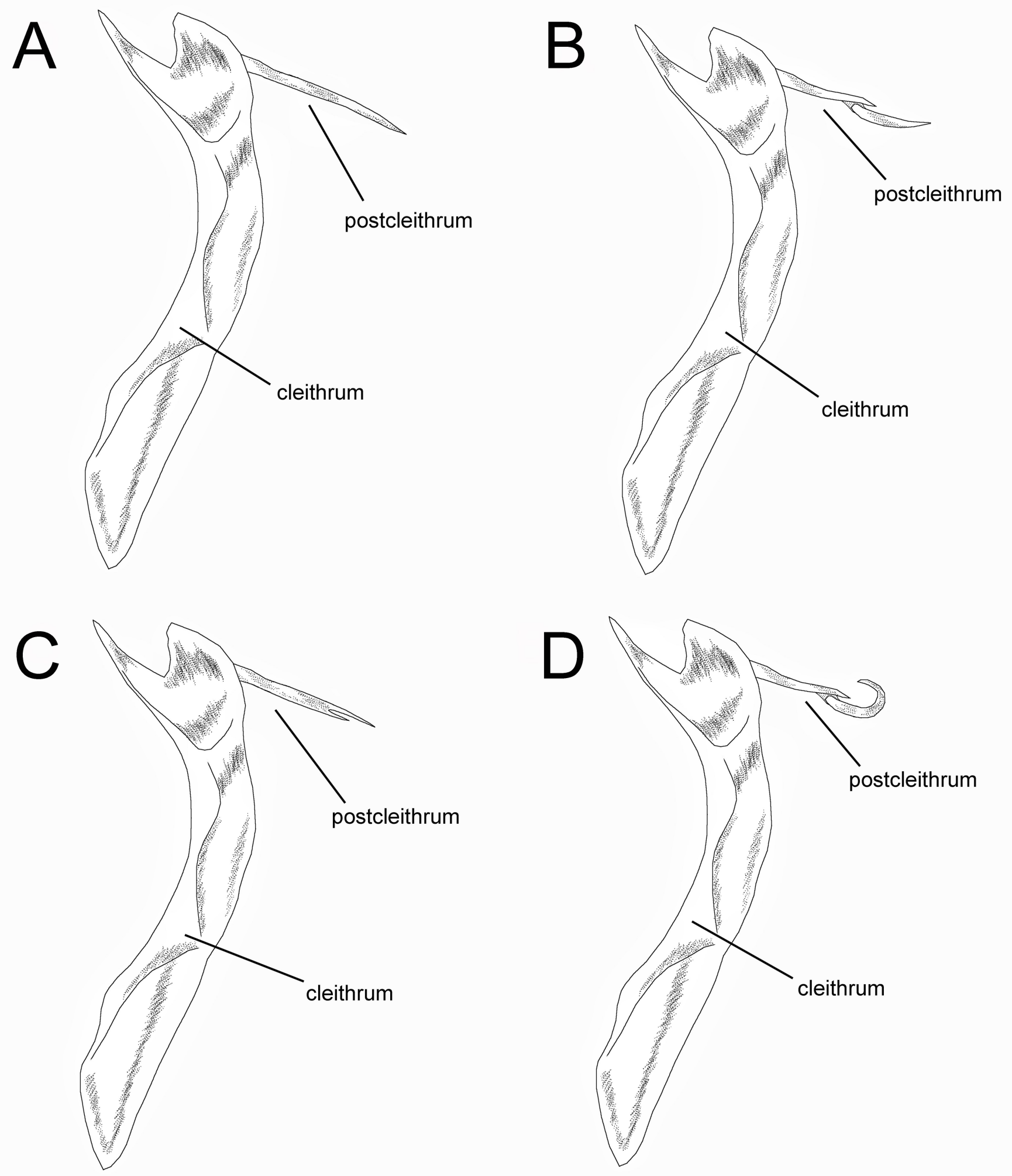

Figure 4. Different shapes of sac-supporting postcleithrum: A, single; B, double; C, forked; D, curved. 
Table 3. Component loadings of the first two principal components for morphometric characters in male and female Inimicus sinensis.

\begin{tabular}{lcc}
\hline & Character & \multicolumn{2}{c}{ Principal Components } \\
\cline { 2 - 3 } & \multicolumn{1}{c}{2} & 2 \\
\hline Head width & -0.302 & 0.052 \\
Snout length & -0.394 & -0.216 \\
Orbit diameter & 0.244 & -0.593 \\
Upper-jaw length & -0.432 & -0.241 \\
Lower-jaw length & -0.380 & -0.332 \\
Pre-dorsal-fin length & -0.382 & -0.293 \\
Pre-anal-fin length & -0.377 & 0.388 \\
Anal-fin base length & 0.274 & -0.442 \\
\hline Percent of variances explained & 45.65 & 16.64 \\
\hline
\end{tabular}

Table 4. Correlation of the different morphometric characters to the first two principal components.

\begin{tabular}{lcc}
\hline & \multicolumn{2}{c}{ Principal components } \\
\cline { 2 - 3 } Head width & -0.577 & 2 \\
Snout length & -0.753 & 0.060 \\
Orbit diameter & 0.465 & -0.249 \\
Upper-jaw length & -0.826 & -0.684 \\
Lower-jaw length & -0.726 & -0.278 \\
Pre-dorsal-fin length & -0.731 & -0.383 \\
Pre-anal-fin length & -0.721 & -0.338 \\
Anal-fin base length & 0.523 & 0.447 \\
\hline
\end{tabular}


those of the anterolateral pore (above). All sacs were found to contain an unidentified hardened substance (Fig. 2C) after preservation (milky in fresh specimens).

A similar pore was found in all species of Inimicus (Inaba $\&$ Motomura, 2018) and was used to categorize the genus into three categories, based on the number of pores. Matsunuma \& Motomura (2018) also reported the presence of a pore above the pectoral-fin base of species of Minous, similarly attached to a sac under the skin, but no association with other organs was found.

\section{Conclusions}

Distinguishing morphological characters of male and female I. sinensis are presented. Sexual dimorphisms are apparent on this species, female samples have bigger head and body region. In contrast, males have longer external features. However, the observed variations might not be enough to discriminate sexes externally due to overlapping morphological characters of the fish when they had almost the same sizes. The differences were commonly observed in the larger individuals, especially in females. Additionally, a cartilaginous sac attached with the pore at the anterolateral surface of the body behind the opercular margin and small pores above the lateral-line were found in this fish. The function of these pores with attached sac is unknown, hence, it is something that must be studied in the future.

\section{Acknowledgments}

We are especially grateful to volunteers and students (particularly K. Fujiwara, S. Tashiro, H. Hata, B. Jeong, S. Chungtanawong, H. Wada, A. Bandai, K. Kawama, T. Uejo, S. Morishita, J. Nakamura, J. Taguchi and M. Araki) at KAUM, and Dr. Ryuta Terada and Ms. Iris Borlongan for their kind assistance during the first author's visit to their institutions. Gratitude is also extended to Dr. Harold Monteclaro, Dr. Maria Celia D. Malay, and Dr. Wilfredo L. Campos for their valuable comments and suggestions for the improvement of the study, and to Mr. Hardy (Ngunguru, New Zealand) for reviewing and editing the manuscript. The first author gratefully acknowledges a scholarship under The Program for Receiving International Research Students for The Spirit of Enterprise Foundation at Kagoshima University, Global Initiative Center, Kagoshima University, Kagoshima, Japan, and Department of Science and Technology Science Education Institute (DOST-SEI), Accelerated Science and Technology Human Resource Development Program-National Science Consortium Component (ASTHRDP-NSC) of the Philippine government.

\section{Literature Cited}

Barnett, A. \& D.R. Bellwood, 2005. Sexual dimorphism in the buccal cavity of paternal mouthbrooding cardinalfishes (Pisces: Apogonidae). Marine Biology, 148: 205-212. doi: 10.1007/s00227-005-0052-z

Bhatta, S., T. Iwai, C. Miura, M. Higuchi, S. ShimizuYamaguchi, H. Fukada \& T. Miura, 2012. Gonads directly regulate growth in teleost. Proceedings of the National Academy of Sciences, U.S.A.,109(28): 11408-11412. Retrieved from www.pnas.org/cgi/doi/10.1073/ pnas. 1118704109

Carvalho, G.R., 1993. Evolutionary aspects of fish distribution: Genetic variability and adaptation. Journal of Fish Biology, 43(Supplement A): 53-73.

Eschmeyer, W.N., 1969. A systematic review of the scorpionfishes of the Atlantic Ocean (Pisces:

Scorpaenidae). Occasional Papers of the California Academy of Sciences, 79: 1-130.

Eschmeyer, W.N., K.V. Rama-Rao \& L.E. Hallacher, 1979. Fishes of the scorpionfish subfamily Choridactylinae from the western Pacific and the Indian Ocean. Proceedings of the California Academy of Sciences, 4th Series, 41(21): 475 -500 .

Ferri, J., M. Petric \& S. Matic-Skoko, 2010. Biometry analysis of the black scorpionfish, Scorpaena porcus (Linnaeus, 1758) from the eastern Adriatic Sea. Acta Adriatica, 51(1): $45-53$.

Fewings, D.G. \& L.C. Squire, 1999. Notes on reproduction in the estuarine stonefish Synanceia horrida. In: SPC Live Reef Fish Information Bulletin \#5, 31-33.

Hedrick, A.V. \& E.J. Temeles, 1989. The evolution of sexual dimorphism in animals: Hypotheses and tests. Trends in Ecology and Evolution, 4(5): 136-138. doi: https:// doi.org/10.1016/0169-5347(89)90212-7.

Herler, J., M. Kerschbaumer, P. Mitteroecker, L. Postl \& C. Sturmbauer, 2010. Sexual dimorphism and population divergence in the Lake Tanganyika cichlid fish genus Tropheus. Frontiers in Zoology, 7(4): 1-10. doi:10.1186/1742-9994-7-4.

Ibor, O.R., G. Eni, A.B. Andem, A. Joseph \& A.V. Chukwuka, 2017. Sexual dimorphism in black jaw tilapia (Sarotherodon melanotheron) and banded jewelfish (Hemichromis fasciatus) from the Great Kwa River, Calabar, Nigeria. Croatian Journal of Fisheries, 75: 122131. doi: $10.1515 / \mathrm{cjf}-2017-0016$.

Inaba, T. \& H. Motomura, 2018. Review of the Indo-West Pacific genus Inimicus (Synanceiidae: Choridactylinae). 
Zootaxa, 4482(1): 52-90. doi: 10.11646/zootaxa.4482.1.2

Kobelkowsky, A., 2004. Sexual dimorphism of the flounder Bothus robinsi (Pisces: Bothidae). Journal of Morphology, 260: 165-171. doi: 10.1002/jmor.10218

Lenarz, W.H. \& T.W. Echeverria, 1991. Sexual dimorphism in Sebastes. Environmental Biology of Fishes, 30: 71-80.

Matsunuma, M. \& H. Motomura, 2018. Three new species of the Indo-Pacific stingfish genus Minous (Synanceiidae: Minoinae) with redescriptions of $M$. trachycephalus (Bleeker 1855) and M. pictus Günther 1880. Zootaxa, 4455 (2): 201. doi: 10.11646/zootaxa.4455.2.1

Motomura, H. \& S. Ishikawa, 2013. Fish collection building and processing manual. English edition. The Kagoshima University Museum, Kagoshima and the Research Institute for Humanity and Nature, Kyoto. 70 pp.

Motomura, H., C.D. Paulin \& A.L. Stewart, 2005. First records of Scorpaena onaria (Scorpaeniformes: Scorpaenidae) from the southwestern Pacific Ocean, and comparisons with the Northern Hemisphere population. New Zealand Journal of Marine and Freshwater Research, 39: 865-880.

Okuda, N., I. Tayasu \& Y. Yanagisawa, 1998. Determinate growth in a paternal mouthbrooding fish whose reproductive success is limited by buccal capacity. Evolutionary Ecology, 12: 681-699.

Oliveira, R.F \& V.C. Almada, 1995. Sexual dimorphism and allometry of external morphology in Oreochromis mossambicus. Journal of Fish Biology, 46: 1055-1064.

Ostrand, K.G., G.R. Wilde, R.E. Strauss \& R.R. Young, 2001. Sexual dimorphism in plains minnow, Hybognathus placitus. Copeia, 2: 563-565. Retrieved from http:// dx.doi.org/10.1643/0045-8511(2001)001[0563:SDIPMH] 2.0.CO;2

Parker, G.A., 1992. The evolution of sexual size dimorphism in fish. Journal of Fish Biology, 41(Supplement B), 1-20.

Peskov, V.N. \& L.G. Manilo, 2016. Sex differences and sex identification in the small-scaled scorpionfish, Scorpaena porcus (Scorpaenidae, Scorpaeniformes). Vestnik zoologii, 50(4): 355-362.

R Core Team., 2018. R: A language and environment for statistical computing. $\mathrm{R}$ Foundation for Statistical Computing, Vienna, Austria. URL https://www.Rproject.org/.

Smith, W.L. \& W.C. Wheeler, 2006. Venom evolution widespread in fishes: A phylogenetic road map for the bioprospecting of piscine venoms. Journal of Heredity, 97 (3): 206-217. doi:10.1093/jhered/esj034

Schoenfuss, H.L. \& R.W. Blob, 2007. The importance of functional morphology for fishery conservation and management: Application to Hawaiian amphidromous fishes. Biology of Hawaiian Streams and Estuaries. Edited by N.L. Evenhuis, and J.M. Fitzsimons. Bishop Museum Bulletin in Cultural and Environmental Studies, 3: 125-141.

Takashima, F. \& T. Hibiya, 1995. An Atlas of Fish Histology Normal and Pathological. Second Edition. Kodansha Ltd., Tokyo. pp. 128-153.

Wearmouth, V.J. \& D.W. Sims, 2008. Sexual segregation on marine fish, reptiles, birds and mammals: Behaviour patterns, mechanisms and conservation implication. Advances in Marine Biology, 54: 107-170. 